\title{
Design gráfico cambiante para marcas hipermodernas
}

\section{Changeable graphic design to hypermodern} brands

Rudinei Kopp ${ }^{1}$

Resumo Neste artigo são analisados os logotipos das marcas Norwegian University of Life Sciences, Nordkyn e MIT Media Lab. Esses trabalhos revelam uma nova face do "design gráfico cambiante" (KOPP, 2002) e estão identificados com um momento caracterizado, nos termos de Gilles Lipovetsky, como hipermodernidade. As marcas analisadas revelam as potencialidades e os riscos dessa época, servindo como dispositivos para a excitação do hiperconsumo e da hiperindividualidade.

Palavras-chaves: Design gráfico cambiante; Marcas; Hipermodernidade

\begin{abstract}
In this article the logotypes of brands from the Norwegian University of Life Sciences, Nordkyn and MIT Media Lab are analyzed. These works reveal a new face of "changeable graphic design" (KOPP, 2002) and are identified as a moment characterized, by Gilles Lipovetsky term, as hypermodernity. The brands analyzed have shown the potentials and the risks that can be used to excitation of hyperconsumption and hyper-individuality.
\end{abstract}

Keywords: Changeable graphic design; Brands; Hypermodernity

\footnotetext{
${ }^{1}$ Universidade de Santa Cruz do Sul - UNISC, Santa Cruz do Sul, RS, Brasil.

E-mail: rudinei@unisc.br
} 
Este texto analisa um fenômeno - o design gráfico cambiante - que tem se revelado como uma forma bastante recorrente nas soluções em identidade visual de inúmeras marcas. Isso fica evidente, a título de exemplo, quando a principal rede de TV do Brasil - a Globo - adota variações inéditas (dentro do contexto da própria emissora) de cores na aplicação da sua marca nas assinaturas da programação e em diversas peças promocionais a partir do final de 2013.

As pesquisas que têm como pretensão estudar a produção visual tendem a considerar e a reunir material de análise a partir de trabalhos realizados por profissionais ou empresas especializadas no ramo. Quanto mais notória essa produção se torna, maior é a probabilidade de algum pesquisador considerar o material como sinal de um tempo ou como indicador de algum fenômeno em curso ou parte de um conjunto que seja capaz de compor alguma categoria.

Quando Hollis (2000, p. 218-219) dedica uma parte de Design gráfico: uma história concisa ao "logotipo transmutável" criado por Helmut Schmidt-Rhen (diretor de arte da GGK, na Alemanha) para o jornal Literatur in Köln (conhecido como Lik), ele leva em consideração a curiosidade que essa marca representava em 1974. Tratava-se de uma marca projetada para que, a cada edição do periódico, as letras de "Lik" se apresentassem de forma diferente. Extraordinariamente, em relação ao que se via na década de 1960 e no início dos anos 1970, era um projeto nada funcionalista, pouco preocupado com alguma intenção de pregnância ou constância visual, e desconsiderava a repetição e a ordem como alicerce da identidade visual.

Para Phillip Meggs e Alston Purvis (2009, p. 10), por exemplo, o registro e a análise do que foi feito ou se faz em design, em termos de relevância histórica, depende de como essa produção se conecta às tendências e às preferências culturais de determinada época através de combinações com a vida social, política e econômica. O design, para Meggs e Purvis, é capaz de expressar o zeitgeist de uma época por ter um caráter imediato de representação. Por esse viés, é possível considerar 
que a marca do Lik era, naquele momento, muito mais uma curiosidade, uma fagulha do que uma expressão consistente e abrangente da época.

De qualquer forma, já havia uma intenção de significado no conjunto de logotipos que não se repetiam. Soluções em identidades visuais que deixam transparecer a fluidez e a efemeridade nos seus traços e nas suas cores e que consideram isso parte clara da sua personalidade tornam-se visíveis a públicos mais amplos nos anos 1980, a partir da notoriedade alcançada pela MTV. No final dos anos 1990 e no início do novo milênio, já são percebidos mais trabalhos que deixam de considerar as identidades fixas como principal solução para suas marcas e produtos. É por conta dessa percepção que pesquisadores passam a organizar seus estudos em torno desse fenômeno por meio das interpretações resultantes das interseções entre design e sociedade.

Um desses estudos foi produzido por Kopp (2002) e a terminologia adotada para intitular o fenômeno e o livro foi "design gráfico cambiante”. A amostragem da pesquisa, naquele instante, analisou um conjunto de capas de revistas (Raygun, Matiz, Sexta-feira e Big) produzidas a partir de meados dos anos 1990 e que não possuíam padronização visual em seus projetos gráficos. Sinteticamente, é possível afirmar que esses veículos eram dirigidos a consumidores muito específicos; além de serem completamente associadas às expressões do pós-modernismo no design, nas expressões culturais e nas formas de consumo.

Mais de quatro décadas depois do experimento captado por Hollis, sistemas de identidades visuais ou projetos gráficos cambiantes (também podem ser designados como mutantes, flexíveis ou dinâmicos) fazem parte do repertório técnico e criativo de quem trabalha e pesquisa assuntos ligados ao design ou à comunicação visual. Irene van Nes (2012) publicou, em 2012, uma compilação de projetos gráficos cambiantes chamada Dynamic identities: how to create a living brand, tornando essa sensação ainda mais palpável.

A coletânea revela a dimensão que esse tipo de opção em design alcançou e mostra, na segunda edição (2013), quase 100 exemplos de 
marcas (ela acrescentou 12 novos exemplos em relação à edição de 2012) que adotaram alguma forma de flexibilidade visual em suas identidades. ${ }^{2} \mathrm{O}$ livro é bem ilustrado e são apresentados, em cada caso, junto com algumas aplicações da marca, um resumo sobre o conceito e a empresa/instituição que adotou a solução.

Documentos desse gênero podem mostrar conjuntos que, sem eles, acabariam sendo percebidos apenas de forma fragmentada. Outra indicação que também merece atenção são as categorias propostas por Nes (2013). A autora divide os exemplos em seis grupos: recipiente, papel de parede, DNA, fórmula, customizado e gerador.

A última categoria, aquela que merecerá uma reflexão mais profunda aqui, é a que se pode traduzir como geradora ou programável. Nesse grupo estão os projetos que usam recursos tecnológicos para fazer com que as identidades sejam capazes de reagir a dados externos a partir de algum sistema informatizado que responda a isso. Esses dados podem ser informações sobre o tempo, notícias, tuítes, número de visitantes, status de algum projeto, dia do ano, preferências pessoais e assim por diante. Nes (2013) relaciona os seguintes casos nesse bloco: USA Today, Oppenheim, RAU, Casa da Música, House of Visual Culture, Lovebytes 2007, Pigmentpol, Lesley Moore, Baltan Laboratories, My Tech Campus, MIT Media Lab, Cinemetrics, Z33, Dezeen Watch Store, The Brno House of Arts, Norwegian University of Life Sciences, Ziens-Wijze, Odooproject, De Treeswijkhoeve, Onedotzero, Orchestre Symphonique Genevois, TV Asahi, Esquire, Dokfest Lounge, Seconde Nature, Café King, Evolving Logo, Frac Centre, Wikipedia e Visit Nordkyn.

\footnotetext{
2 A Dopress Books (Londres) publicou, em 2013, uma coletânea intitulada Dynamic logo com mais de 100 exemplos de identidades visuais dinâmicas. A divisão é feita apenas pelos segmentos de origem das marcas (comércio, serviços, arquitetura, cultura, turismo etc.).
} 
Neste artigo serão apresentados e analisados três projetos que possuem características capazes de estimular a reflexão sobre os caminhos das marcas e a maneira como isso está relacionado a esses primeiros anos do século XXI. São projetos que ganharam bastante notoriedade (através de premiações, periódicos e blogs de design, por exemplo) e que, de uma forma ou de outra, serviram ou servem como referência para os demais, por terem iniciado ou aprimorado essa concepção de marca. Por esse motivo, a seleção recaiu sobre esses casos.

\section{Norwegian University of Life Sciences, Nordkyn e MIT Media Lab}

Em 2008 (as aplicações iniciaram em 2010), o estúdio norueguês Tangram Design projetou a identidade visual para a Norwegian University of Life Sciences. Foi criada uma marca aparentemente simples e objetiva, cuja estrutura visual pode ser descrita como um símbolo formado por 21 bolas de tamanhos variáveis de uma aplicação para outra (Figura 1). Essa simplicidade visual, no entanto, é administrada por um programa que faz esse biograma - essa é a forma como o estúdio batizou a marca/sistema - apresentar organizações visuais diferentes de um dia para o outro.

Cada um dos 21 círculos pode se manifestar em sete tamanhos diferentes a cada aplicação (Figura 2). Esse conjunto de círculos segue o princípio de que é uma marca viva e que, para cada dia, há uma combinação diferente. $\mathrm{O}$ momento que se considera o inicial, com as 21 bolinhas no tamanho mínimo, é o dia da fundação da universidade: $1^{\circ}$ de outubro de 1859. Depois disso, cada dia tem um biograma diferente. Isso tem permitido uma gama imensa de variações. O programa que gerencia o "comportamento" da marca está incorporado ao site da universidade (http://biogram.umb.no/) e é possível, por exemplo, informar a data de nascimento de alguém e gerar instantaneamente a marca que equivale a esse dia. Esse princípio é aplicado aos cartões de visita dos funcionários da instituição. 

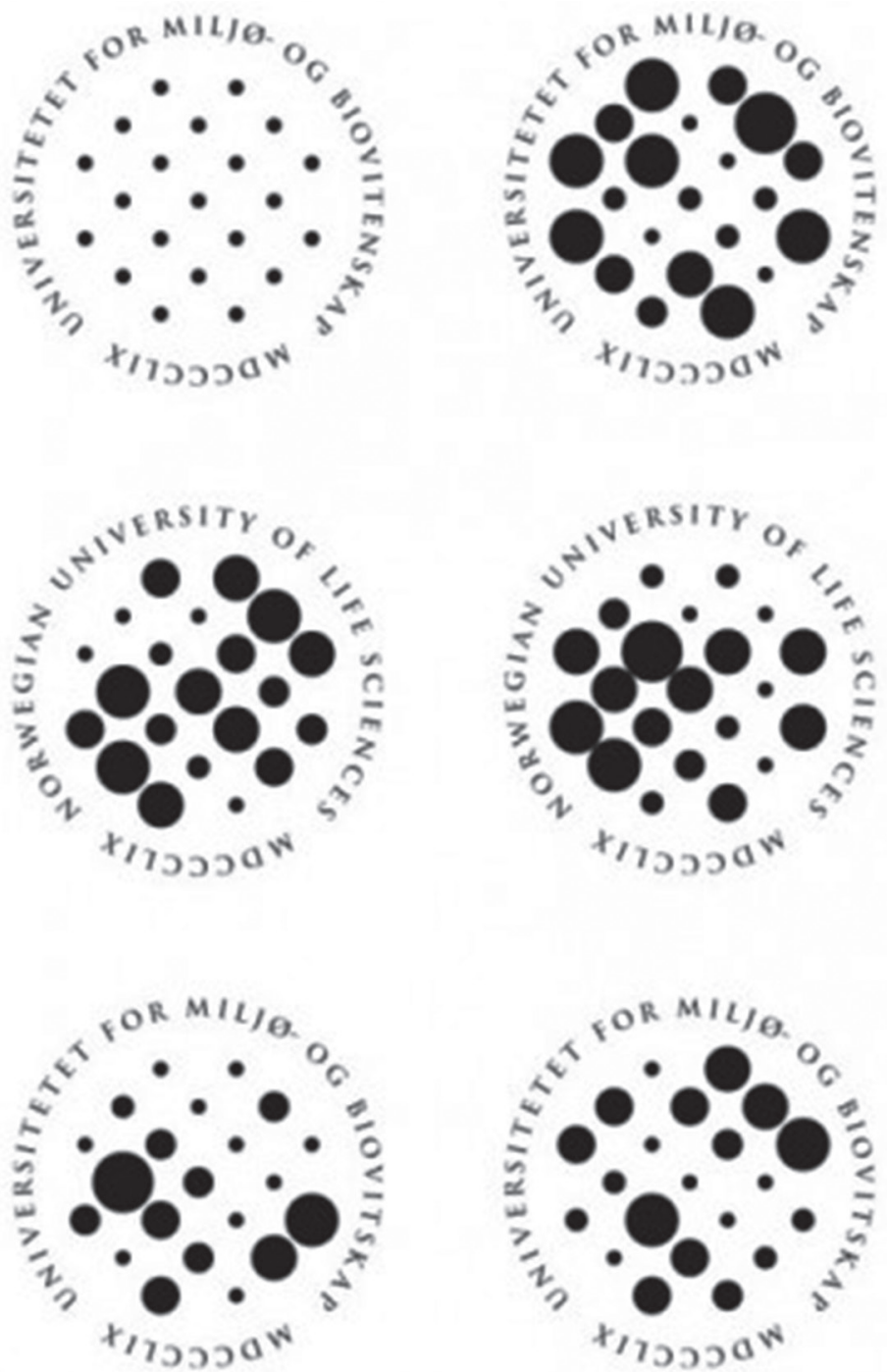

Figura 1: Variações diárias do logo da Norwegian University of Life Sciences Fonte: www.tangram.no 


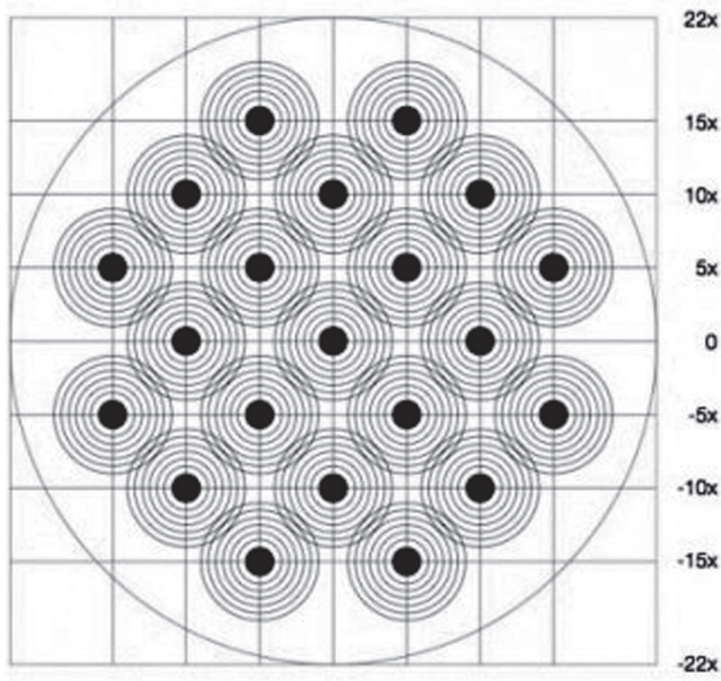

Figura 2: Estrutura visual da marca.

Fonte: www.tangram.no

O princípio criativo está alicerçado na ideia de que a universidade trabalha sobretudo com a vida, suas variações, seus ciclos e suas adaptações. A marca emula isso a partir de um sistema gerativo que aleatoriamente cria combinações para cada dia. Essa simulação de organismo vivo, no entanto, tem um rigoroso sistema matemático em sua base. Essencialmente, trata-se de combinações de figuras geométricas dispostas de acordo com 21 centros geométricos rigidamente mantidos de uma mutação para outra.

O símbolo foi organizado para ser um dispositivo capaz de reagir a cálculos aleatórios demandados por um algoritmo randômico. Como a quantidade de combinações excede nove dígitos, as possibilidades visuais podem ser consideradas humanamente infinitas e o arranjo é um problema objetivamente matemático. A marca tem uma vida autônoma naquilo que se refere a como ela será daqui a cinco, 15 ou 50 anos. Suas transformações, por outro lado, são ditadas unicamente pelo passar dos dias. Não há interações ambientais ou reações de acordo com quem demandará ou visualizará a marca. 
Em 2010, o estúdio de design Neue - também norueguês - foi contratado por dois municípios (Gamvik e Lebesby) para desenvolver a marca para um projeto turístico - intitulado Visit Nordkyn - na península de Nordkyn, uma região ao norte da Noruega. Essa área apresenta um cenário natural muito próximo do selvagem, com paisagens intocadas, animais nativos e o instável e rigoroso clima ártico. As condições meteorológicas são radicais, há grandes oscilações de temperatura e tempestades surgem de um momento para o outro. Essas características produziram um posicionamento para o trabalho criativo: "onde a natureza reina". ${ }^{3}$

Esse fio condutor levou ao desenvolvimento de uma marca que se comporta de acordo com as variações do tempo. O Instituto Meteorológico Norueguês é capaz de fornecer dados atualizados constantemente sobre o tempo; isso acabou se convertendo em um elemento verbal variável da marca e, principalmente, transformou-se em um gerador de informações que altera a cor do símbolo - variando com a temperatura - e transforma a própria forma do hexágono - de acordo com a direção e a velocidade do vento (Figura 3).

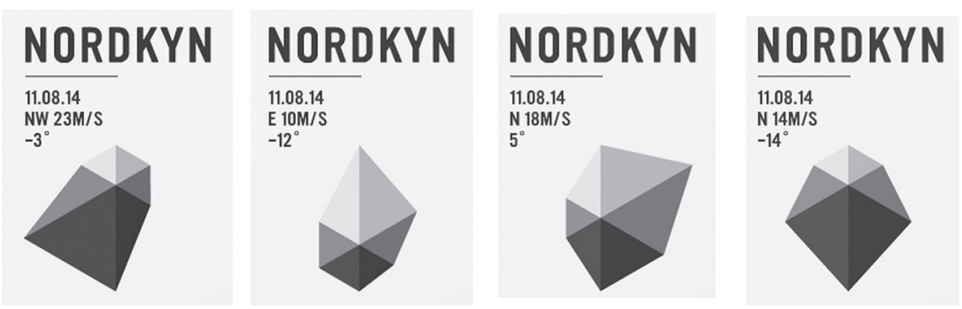

Figura 3: Variações da marca Nordkyn de acordo com a direção do vento e as oscilações de temperatura.

Fonte: www.neue.no

Essa atualização da marca é feita a cada cinco minutos no site institucional. O sistema informatizado, alimentado pelo instituto, dá vida constante à identidade visual na internet. As aplicações sobre suportes

${ }^{3}$ http://www.visitnordkyn.com/About-Nordkyn/About-Visit-Nordkyn. Acesso em: 11 ago. 2014. 
estáticos também não são padronizadas e podem ser feitas de acordo com a combinação climática de uma paisagem, por exemplo, para algum anúncio publicitário.

A marca oferece uma narrativa incessante sobre si e sobre o lugar que ela representa. É capaz também de criar uma experiência pessoal com os visitantes, uma vez que existe a possibilidade de fazer o download do logotipo no site de acordo com o dia e o horário no qual o turista viveu as formas como a natureza se manifestou em Nordkyn.

A marca tem um sistema que lhe dá independência na maneira como irá se comportar visualmente, mas mantém um conjunto fixo de elementos que é sempre repetido: tipografia, paleta de cores, posição do símbolo, grade de movimentação. Essa grade é hexagonal e serve como um sistema que define os limites da forma que mostrará a direção do vento (Fig. 4). A marca é aleatória e imprevisível desde que respeite o ordenamento preexistente.
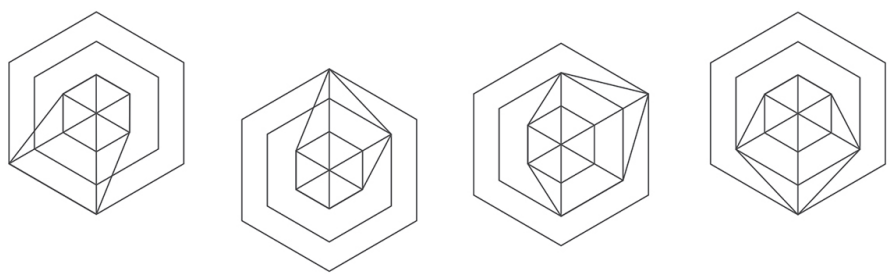

Figura 4: Interpretação visual da grade aplicada às variações.

Fonte: Ilustração do autor

A terceira marca que merece destaque e análise foi elaborada em 2011 pela TheGreenEyl e por E Roon Kang para o MIT Media Lab. O logo é formado basicamente por três quadrados pretos que se movem num diagrama não aparente de nove por nove quadrados (Figura 5). Esses quadrados projetam cores (vermelho, azul, verde, laranja, amarelo etc.) e formam um novo quadrado três vezes maior que o primeiro. As cores se sobrepõem e criam arranjos e nuances completamente novos a cada combinação desse conjunto (Figura 6). 

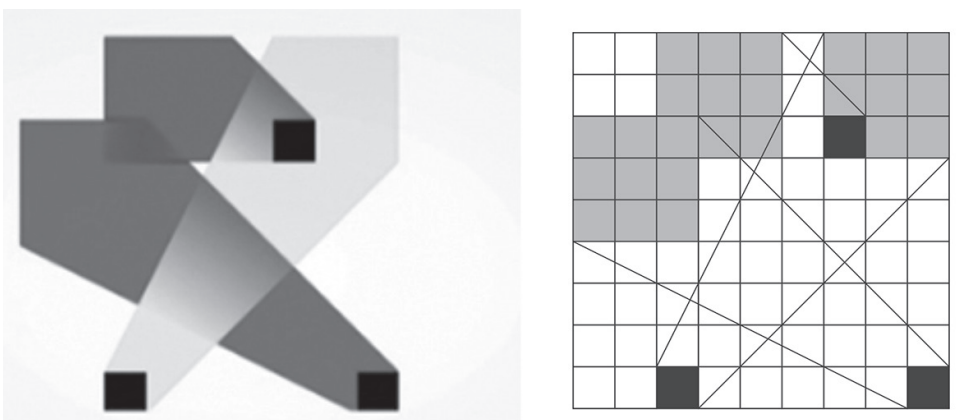

Figura 5: Aplicação da marca do MIT Media Lab e interpretação visual do grid que ordena os quadrados e as projeções.

Fonte: www.eroonkang.com/; ilustração do autor

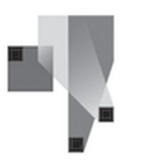

MIT MEDIA LAB

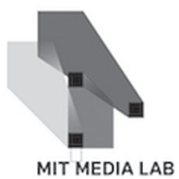

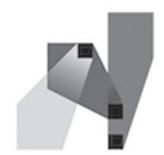

MIT MEDIA LAB

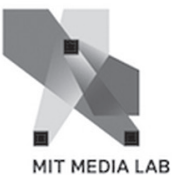

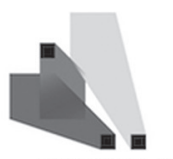

MIT MEDIA LAB

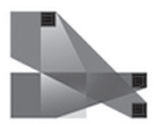

MIT MEDIA LAB

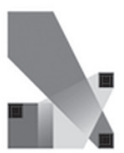

MIT MEDIA LAB

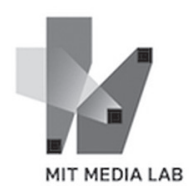

Figura 6: Aplicações individuais da marca.

Fonte: www.eroonkang.com/

O conceito, de acordo com os criadores, ${ }^{4}$ é de que as três formas representam as qualidades da comunidade Media Lab: criatividade, diversidade e inspiração mútua. Esse conceito torna-se ainda mais visível e consistente pelo fato de essa marca ser gerada para cada um dos alunos, professores e funcionários, que podem usar essa variação de marca única em cartões de visita, páginas pessoais da web ou versões animadas para apresentações de trabalhos e projetos.

\footnotetext{
${ }^{4}$ http://thegreeneyl.com/mit-media-lab-identity-l. Acesso em: 2 ago. 2014.
} 
Os logos são gerados a partir de um programa que pode ser manipulado e adequado a certas inclinações pessoais manifestadas pelos usuários. Ao final, um algoritmo define a exclusividade da combinação e mantém o conjunto suficientemente reconhecível como parte de um todo.

Para E Roon Kang, ${ }^{5}$ essa solução permite traduzir a ideia de um grande grupo formado por pessoas das mais diversas origens que são capazes de se inspirar a se reunir e a criar, coletivamente, novas visões para o futuro. Esse princípio, traduzido pela marca, é capaz, então, de revelar a essência do trabalho do MIT: "uma redefinição constante do que mídia e tecnologia significam hoje”.

Esses três projetos compartilham características além do fato de as marcas serem geradas e administradas por um software e de serem cambiantes, que merecem ser destacadas. Eles têm uma origem rigorosamente matemática e são baseados em diagramas com múltiplas possibilidades dinâmicas. A aleatoriedade das formas que essas marcas permitem em seus arranjos são predefinidas por um sistema modular e por proporções de formas estáveis, mas que permitem, mesmo assim, muitas disposições (re)combinadas. Ao mesmo tempo que as aplicações podem ser variadas para cada instante, elas mantêm um reconhecimento alicerçado em formas geométricas simplificadas e em cores facilmente memorizáveis.

Essas marcas, mesmo variando o tempo todo, conseguem manter uma boa capacidade de memorização. Não é possível afirmar que elas consigam alcançar a mesma pregnância individual que símbolos como o da BMW, da Target ou da Texaco possuem, mas são capazes de criar uma ligação visual forte às suas marcas através da constância na manutenção de elementos visuais que não se alteram.

Nos três casos, o estilo tipográfico e a diagramação dos elementos verbais são trabalhados sem alterações de uma aplicação para outra. São tipos simplificados, neutros e de fácil legibilidade. Eles servem como legendas limpas e objetivas para os símbolos e não disputam a atenção visual dos públicos.

${ }^{5}$ http://www.eroonkang.com/projects/mit-media-lab-identity/. Acesso em: 4 ago. 2014. 
Essas descrições aparentemente aproximam essas marcas de um ideário modernista no design. Por outro lado, elas estão muito distantes de serem marcas que pretendam provocar a memorização através de algum vínculo visual rígido e imutável. Elas vivem um outro momento além dos debates sobre Modernidade/modernismo(s) e Pós-Modernidade/ pós-modernismo(s). Essas análises alcançaram sua culminância nos anos que marcaram a virada do milênio e revelaram, quase sempre, uma boa dose de diagnósticos que eram facilmente compartilhados, o que foi bastante visível nas práticas e nos estudos envolvendo design. Debates específicos dessa natureza podem ser vistos em Lupton e Miller (1996), Cauduro (2000), Gruszynsky (2000), Kopp (2002), Poynor (2003) e Bomeny (2012).

Definir o tempo contemporâneo é sempre um risco, mas, ainda assim, é uma tarefa fundamental para registrar e categorizar fenômenos em curso. As percepções ficam, assim, depositadas e registradas não apenas como sinais de produção, mas também como vestígios de avaliação e pesquisa. Esse modo de pensamento faz com que se dê a devida atenção à designação proposta por Gilles Lipovestky: os tempos hipermodernos.

\section{Tempos hipermodernos}

A caracterização que se destacava sobre a sociedade no final do século XX estava bastante identificada ainda com as noções e as interpretações acerca de uma condição ou de um tempo pós-moderno. Termos como flexível, efêmero, fugidio, cambiante, liquefeito, fragmentado, entre tantos, eram usados de forma constante para caracterizar as últimas duas ou três décadas. Mesmo que muitos pesquisadores e designers já considerassem o pós-modernismo como algo morto, como uma página virada, para Poynor (2003, p.10), o design entrou no novo século exibindo "sintomas de pós-modernismo".

Poynor resume as características atribuídas ao pós-modernismo, em oposição ao modernismo, no design da seguinte forma: 
Se o modernismo buscava criar um mundo melhor, o pós-modernismo (...) parece aceitar o mundo como ele é. Ao passo que o modernismo frequentemente atacava a cultura comercial de massa, argumentando, a partir de sua perspectiva de superioridade, saber o que era melhor para o povo, o pós-modernismo se envolve em uma relação de cumplicidade com a cultura dominante. No pós-modernismo, as distinções hierárquicas do modernismo entre a valorizada "alta" cultura e a "baixa" cultura entram em colapso e as duas se tornam possibilidades iguais no mesmo plano. A erosão dessas velhas fronteiras permite que novas formas híbridas floresçam, e muitas das mudanças observadas no design dos últimos anos, que tomou para si algumas das características autoexpressivas da arte, só fazem sentido nesses termos (POYNOR, 2003, p. 11).

Esse modo de expressão do design não acontece de forma desconectada da cultura que o envolve, abastece e retroalimenta: "os produtos da cultura pós-moderna tendem a ser classificados por características como fragmentação, impureza da forma, ausência de profundidade, indeterminação, intertextualidade, pluralismo, ecletismo e por um retorno ao vernacular" (POYNOR, 2003, p. 12). Em oposição à pretensão - ao modo modernista - à originalidade, esta deixa de ser o principal valor $\mathrm{e}$ objetivo do que se produz. Assim como o design foi transformado pelo modernismo - seja na fase mais experimental, seja na fase mais dogmática -, ele também foi transformado pelo pós-modernismo e por suas inúmeras faces, provocações e experimentações. O que merece atenção é justamente a forma como esses momentos conectam a cultura e o design e, assim, geram alguma sombra que revele os contornos desses tempos muito recentes e, por isso mesmo, difíceis de serem definidos.

Os termos que procuram caracterizar as últimas quatro décadas são abundantes; ${ }^{6}$ nessa leva de propostas conceituais, merece destaque, para ambições deste texto, o termo defendido por Lipovetsky: hipermodernidade. Lipovetsky notabilizou-se por estudar a contemporaneidade a partir de interações que envolvem dados sobre os mercados globais, a

\footnotetext{
${ }^{6}$ Por exemplo: pós-modernidade (Lyotard), segunda modernidade (Beck), modernidade líquida (Bauman), metamodernidade ou modernidade tardia (Giddens), ultramodernidade (Gauchet e Zarka).
} 
produção industrial, as tendências da moda e do consumo, o comportamento humano, junto com um profundo conhecimento em teorias sociais, antropológicas e filosóficas. Essa abordagem e suas reflexões são relevantes para entender como o design gráfico cambiante pode ser compreendido atualmente.

Lipovetsky (2007) considera que a atualidade corresponde a um terceiro momento da mercantilização moderna. A primeira fase teria se iniciado por volta de 1880 e durado até o final da Segunda Guerra. São as décadas que testemunham o desenvolvimento dos grandes mercados, o avanço dos sistemas de transportes, das tecnologias de comunicação, do comércio e dos meios de produção em série. Isso criou as condições para uma era de produção em massa de mercadorias padronizadas. O consumidor e o mercado modernos são forjados a partir da oferta crescente de produtos que passam a contar, cada vez mais, com marcas que expressam os mais diversos tipos de promessas, garantias e associações. Com a perda da relevância nos processos de intermediação, a marca e a publicidade passam a oferecer as informações e as sensações que o consumidor usará para realizar uma compra.

A fase seguinte equivale às três décadas do pós-Guerra. A produtividade industrial já alcançou altos níveis e o poder de compra dos trabalhadores, em países desenvolvidos, permite uma vida de consumo democratizado. A organização das formas de produção que possibilitam a manutenção dessa sociedade de consumo de massa está relacionada, nessas décadas, à "especialização, padronização, repetitividade, elevação dos volumes de produção” (LIPOVETSKY, 2007, p. 33). Com esse modelo amadurecido e em expansão, o que se percebe também é a diversificação de produtos e a intenção clara de redução na vida útil das mercadorias: "a ordem econômica ordena-se já parcialmente segundo os princípios da sedução, do efêmero, da diferenciação dos mercados” (LIPOVETSKY, 2007, p. 34). É a fase na qual a publicidade e a mídia "exaltam os gozos instantâneos" e a vida passa de uma "orientação futurista para a "vida no presente". 
A partir do final dos anos 1970, haverá a eclosão de um novo ato nas sociedades com economias desenvolvidas: a fase do hiperconsumo. A partir de então, “ [o] consumo ordena-se cada dia um pouco mais em função de fins, de gostos e de critérios individuais" (LIPOVETSKY, 2007, p. 41). Inicia-se o estágio do consumo emocional das marcas e as relações provocadas a partir daí passarão a criar uma experiência identitária, substituindo ou enfraquecendo as instituições - como a religião e a política - que, tradicional e modernamente, detinham esse papel.

Esse novo momento provoca também outro estágio em relação ao consumo e ao desejo pelo novo. Para Lipovetsky (2007, p. 43-44), “o gosto pela mudança incessante no consumo já não tem limite social, difundiu-se em todas as categorias de idade". A fase em curso transformou a curiosidade em uma "paixão de massa" e fez do "mudar por mudar" "uma experiência destinada a ser experimentada pessoalmente" (LIPOVETSKY, 2007, p. 44). O hiperconsumo intensifica o hedonismo, renovando mercadorias, serviços e símbolos de forma irrefreada. Emerge daí "uma estética do movimento incessante e das sensações fugazes" (LIPOVETSKY, 2007, p. 68).

Essa mudança na perspectiva do consumo surge conjuntamente com as possibilidades de produção e distribuição do pós-fordismo. Diferente de uma lógica baseada na padronização e na repetição de operações como ditames da indústria massificada, os anos 1970 já começam a oferecer condições para produzir, no nível tecnológico, uma variedade de opções e diferenciações experimentadas, até então, apenas por uma elite econômica. Segue-se, então, "uma segmentação extrema, quase ilimitada (...), explorando nichos específicos e micromercados com duração de vida curta" (LIPOVETSKY, 2007, p. 81-82). O mercado passa a ser orientado pela hipersegmentação e pela inovação de opções: “o inovacionismo suplantou o produtivismo repetitivo do fordismo” (LIPOVETSKY, 2007, p. 86).

A torrente de fluxos permanente arrasta não apenas a maneira como o mercado, os consumidores e os sistemas produtivos se organizam. A 
próprio tempo de vida dos produtos culturais, as "obras do espírito", é tocada por essa força que transforma a renovação e a efemeridade em valores simbólicos. Produtos e serviços são anunciados meses ou anos antes de existirem de fato: "o hiperconsumidor já não consome apenas coisas e símbolos, consome o que ainda não tem concretização material" (LIPOVETSKY, 2007, p. 91).

O setor que melhor representa a forma como se constitui esteticamente essa época é o mundo das marcas. É nele que surge e se mantém o repertório que abastece o imaginário do hiperconsumidor e que é capaz de estimular as "relações afetivas" desejadas pelas marcas contemporâneas. Na era do comprador emocional, a marca se torna "onírica e cúmplice", "ela joga consigo mesma e com o consumidor" (LIPOVETSKY, 2007, p. 96).

As marcas deixam de ser apenas indicadores comerciais e constroem "uma cultura, isto é, um sistema de valores, objetivos e mitos" (LIPOVETSKY e SERROY, 2011, p. 10). Os produtos deixam de ser comprados somente por sua utilidade e funcionalidade. A marca supera essa relação e o hiperconsumidor estabelece um outro sentido na relação com o mundo das marcas. Elas servem como "um suplemento da alma, de sonho e de identidade” (LIPOVETSKY e SERROY, 2011, p. 95). As marcas passam a ser capazes de contar histórias sobre si e isso estabelece um significado desejado pelo consumidor. A diferenciação se dá, cada vez mais, pela capacidade de essas marcas produzirem vínculos que denotem valores.

A construção de marcas que possuem uma conexão cultural com os seus consumidores é capaz de transformá-las em motivos para debates e discussões variadas mundo afora. Elas acabam criando ligações entre pessoas justamente por serem capazes de produzir afinidades que, em outros tempos, estavam relacionadas ao mundo das crenças e das ideias: "É sobre a erosão das organizações e das culturas de classe que as marcas triunfam, conferindo referências, segurança, autovalorização aos indivíduos" (LIPOVETSKY e SERROY, 2011, p. 100). 
As questões claramente identificadas com a condição pós-moderna referiam-se: à forma como o universal cedia espaço ao individual; à desaparição ou ao esgotamento das crenças e dos discursos totalizantes; à explosão da lógica do consumo; à diversificação dos gostos e das formas de autoexpressão; e à emersão de identidades múltiplas e fragmentadas. Essas questões foram elevadas a uma condição superlativa. Lipovetsky resume isso considerando a noção de que tudo alcançou um nível 'hiper'.

A hipermodernidade é a modernização constante da própria modernidade. Como Charles (2009, p. 26) sintetiza, "a hipermodernidade apresenta-se como uma modernidade desprovida de qualquer sentido transcendente, funcionando plenamente (...), sem, no entanto, poder justificar o seu próprio funcionamento e parecer conseguir se autolimitar". Charles destaca que os princípios estruturantes da modernidade - o individualismo, a ciência tecnológica, o mercado e a democracia radicalizaram-se e tornaram-se direito imperativo do indivíduo.

É nesse contexto que as marcas que são capazes de construir significados a partir de narrações, de histórias, de diálogos, de identificações, de trocas, de repertórios simbólicos e até de uma intimidade com o consumidor se consolidam nesse início de século. O design transforma-se e revela consciente e inconscientemente essas mudanças e adaptações.

\section{Design para consumidores hipermodernos}

Quando as identidades visuais eram planejadas ao modo modernista, a principal intenção era manter uma expressão visual administrável, previsível e controlável. As aplicações seguiam um receituário e os elementos visuais eram acomodados aos suportes de acordo com ângulos e espaços que respeitavam equações visuais e, assim, garantiam o conceito de coerência e consistência visual em voga. Abandonar o grid e as padronizações - entendidos como manifestações de um discurso ortodoxo e com resultados monótonos e previsíveis - foi uma das formas que os designers influenciados pelo pós-modernismo encontraram para manifestar uma atitude diferente e renovadora em seus projetos. 
Os usos dessas identidades cambiantes e flexíveis foram capazes de dar um ar rejuvenescido às marcas, transmitindo uma atitude que parecia mais adequada às empresas e instituições que pretendiam se comunicar com nichos de públicos menos identificados com as padronizações tratadas com rigor e método.

O que se percebe nesses últimos 10 anos, pelo menos, é uma presença mais clara de marcas que se valem - temporária ou permanentemente - de identidades visuais menos fixas. Se, nos anos 1990, essa forma de elaboração criativa ficou circunscrita a públicos relativamente segmentados e associados a expressões culturais juvenis ou alternativas, o começo do século XXI se revela como a época na qual essas soluções se alastram e deixam de ter tão somente vínculos tribais.

A transformação da marca em símbolo capaz de representar um mundo de subjetividades em seu entorno já está assimilada pelo consumidor e é projetada pela empresa/instituição por trás do símbolo (a marca do Google e seus inúmeros doodles, desde 1998, representa isso com bastante clareza). Pode-se, a essa altura, perceber que a marca encaminha-se para alcançar a capacidade de representar a própria vida e, assim, amplificar os níveis de relacionamento. Ao ter um sistema incorporado - provido por recursos tecnológicos - que seja capaz de dar uma existência aleatória, que reaja ao ambiente ou que se adéque àqueles consumidores que o usam como forma de representação, esse signo se revela como algo capaz de reagir ao mundo de uma maneira que parece ser a dos seres orgânicos. Não se trata apenas de desejá-lo como forma de ostentação e diferenciação; como sinal de identificação tribal ou planetária; como evocador de experiências vividas ou projetadas; ou de ser um disparador do gozo e do bem-estar; ele se transmuta em um ser próximo ao vivente, tão instável e surpreendente quanto a própria vida.

A questão dos suportes para o design é fundamental para poder imaginar como as aplicações podem chegar a um ponto ainda mais 'vivo' na relação com os consumidores. Empresas que já fazem uso de formas cambiantes em suas marcas há um bom tempo, como a MTV, a TV Asahi ou o Google, estabelecem os pontos de contato com os seus 
públicos, principalmente, através de telas. Não se trata, portanto, de um suporte fixo como o papel ou uma fachada. Essa limitação estática, no entanto, é apenas questão de tempo. A incorporação de IPs a objetos já é algo em curso e os recursos tecnológicos que permitem criar telas extremamente finas e flexíveis (vestíveis), capazes de reproduzir informações dinâmicas (através de nanopixels), ao modo dos aparelhos celulares e dos tablets, já são usados restritamente ou estão em teste. Potencialmente, é bastante provável que seja possível haver marcas de tênis (no próprio tênis), por exemplo, que reajam ao seu usuário. Essas reações poderão ser de acordo com sinais fisiológicos imediatos; desejos e opções manifestados pelo próprio usuário; acesso a algum banco de dados capaz de decodificar e reconhecer perfis e predileções; ou, simplesmente, adequações demandadas pela própria fabricante a partir de um centro de informações e de controle de mutações da marca.

As marcas cambiantes, que simulam a vida, lançam desafios conflitantes. A partir de uma abordagem comercial e administrativa, esse recurso será expandido e custeado pelos interesses crescentes em manter um mercado ávido por inovações em produtos amalgamados com qualquer novidade tecnológica e tocados pelo mundo das marcas. Nesse caso, a tendência é que os conflitos sejam apenas de ordem econômica para pôr em operação demandas dessa natureza.

O cenário contemporâneo parece indicar que o ímpeto mercadológico prevalecerá e que isso produzirá, quem sabe, um novo estágio na relação com as marcas, e que isso conseguirá superar a perspectiva cultural das marcas. Se essa relação continuar sendo baseada num sistema de trocas que promete o prazer renovado instantaneamente; que ofereça diferenciais sociais que gerem algum nível de satisfação pessoal ou identificação social; que estimule a conectividade ou a simulação disso; e que ainda seja capaz de produzir significados que provoquem experiências de vida, há um cenário no qual o design desencadeará subjetividades ainda mais complexas e mais impregnadas aos modos de vida.

Essa forma de concepção do design revela um verdadeiro compromisso com a realização da conexão e da expressão absolutamente 
individual: ele é tocado e abastecido pela tecnologia para alcançar a máxima realização dos objetivos traçados, trabalha a ideia do consumidor como objetivo final da sua tarefa e faz com que se reconheça todo indivíduo sobre a Terra como meta do seu projeto. Assim, sem restrições, todos possuem o direito - ou o dever - de usufruir os prazeres da sua pervasividade. Há, nesses termos, o design numa condição hipermoderna.

Para Meggs e Purvis (2009, p. 303), "uma filosofia do design é uma visão meramente ociosa até que alguém crie artefatos que a convertam em uma força concreta no mundo". Os casos analisados são revelações de uma força concreta que está baseada na unificação; em um sistema programático; em método claro e que privilegia formas geométricas; usa grids modulares; divide o espaço linearmente; apresenta sequências; é tipograficamente neutro e objetivo; e que, ao mesmo tempo, é capaz de revelar mutações visuais que potencializam ainda mais a estrutura e o sistema que ordena a identidade visual. Diferente das marcas cambiantes que expressavam, muitas vezes, um fazer poético identificado com algum traço individual, esses sistemas usam a variação como uma espécie de motor para incrementar as intenções individualizantes (em relação ao público) da marca.

Outro ponto que se revela nessas marcas é a capacidade que elas têm de uma gestão praticamente autônoma. Os grids e sistemas que dividiam o espaço e previam distribuições de antemão, eliminando os ímpetos pessoais, foram levados a um estágio superlativo da autonomia de sistemas autogeridos. É o programa que administra e dá vida à marca, faz dela um signo capaz de "saber" como agir nos próximos anos, reagir ao mundo e interagir com as pessoas.

Retomando os termos de Lipovetsky, é possível considerar que o design também se tornou hiper - um hiperdesign - ao revelar a capacidade de, assim como os outros dispositivos que permeiam a vida contemporânea, produzir uma oferta constante de entretenimento, de soluções e interações tecnológicas sem fim e de satisfazer a necessidade/possibilidade de cada indivíduo de manifestar incessantemente suas opções. A publicidade e o design são atividades gêmeas na construção de marcas 
e, por isso, quando Lipovetsky sintetiza que a publicidade, no passado recente, "educava o consumidor" e "agora o reflete" (2007, p. 182), pode-se facilmente compreender o design igualmente como reflexo desse hiperconsumidor.Mesmo que, em termos mercadológicos, um vislumbre desses modos possa gerar êxtase, por outro lado, essa hiperexcitação pode gerar uma fadiga de autorrepresentação do indivíduo. Charles (2009) considera que os tempos hipermodernos descortinam o hiperconsumismo e o hiperindividualismo. São condições amalgamadas e a multiplicidade de produtos cada vez menos padronizados e mais individualizados provoca uma oferta extrema de opções. Essa ascensão do individualismo a um estágio "hiper" está ligado, para Charles, a quatro fatores: perda de expressão e legitimidade das grandes ideologias modernas (questão já destacada por Lyotard e nomeada como "crise das metanarrativas"); desestruturação das regras econômicas tradicionais e transformação do indivíduo em trabalhador e empreendedor em permanente concorrência com os demais; celebração da liberdade individual como forma de fuga às imposições gregárias e como exaltação da unicidade e da diferença em relação aos outros; e difusão e aceitação da ideia de que cada um deve ser o "gestor da própria existência" (CHARLES, 2009, p. 136).

O design cambiante aplicado ao modo gerativo (programado) potencializa o hiperindividualismo e compreende esse traço contemporâneo como uma solução de mercado. Mesmo que os exemplos expostos pareçam localizados e até distantes, é perceptível a potência que essa forma de fazer e pensar design guarda como dispositivo capaz de turbinar ainda mais a relação 'consumidor versus marca' no nível hiperindividual. É algo em pleno curso.

Esse design de transmutações dionisíacas se transforma, agora, num sistema personalizado, autônomo e imprevisível. Mostra várias faces, revela (simula) emotividade e cria vínculos pessoais. Por outro lado, jamais deixa de ser preso a uma gaiola, nunca esquece sua vocação para a eficiência mercadológica e não expressa sinais de autoria. 


\section{Referências}

BOMENY, M. H. W. O panorama do design gráfico contemporâneo: a construção, a desconstrução e a nova ordem. São Paulo: Senac, 2012.

CAUDURO, F. V. Design gráfico \& pós-modernidade. Revista Famecos: mídia, cultura e tecnologia, n. 13, vol. 1, p. 127-139, dez. 2000.

CHARLES, S. Cartas sobre a hipermodernidade ou o hipermoderno explicado às crianças. São Paulo: Barcarolla, 2009.

GRUSZYNSKI, A. C. Design gráfico: do invisível ao ilegível. Rio de Janeiro: 2AB, 2000. HOLLIS, R. Design gráfico: uma história concisa. São Paulo: Martins Fontes, 2000.

KOPP, R. Design gráfico cambiante. Santa Cruz do Sul: Edunisc, 2002.

LIPOVETSKY, G. A felicidade paradoxal: ensaio sobre a sociedade de hiperconsumo. São Paulo: Companhia das Letras, 2007.

LIPOVETSKY, G.; SERROY, J. A cultura-mundo: resposta a uma sociedade desorientada. São Paulo: Companhia das Letras, 2011.

LUPTON, E.; MILLER, A. Design, writing, research: writing on graphic design. Nova York: Phaidon, 1996.

MEGGS, P.; PURVIS, A. História do design gráfico. São Paulo: Cosac Naify, 2009.

NES, I. Dynamic identities: how to create a living brand. 2. ed. Amsterdã: BIS, 2013.

POYNOR, R. No more rules: graphic design and postmodernism. New Haven: Yale University Press, 2003.

Data de submissão: 20/02/2015

Data de aceite: 04/06/2015 